\title{
Pigmented villonodular synovitis
}

INSERM

\section{Source}

INSERM. (1999). Orphanet: an online rare disease and orphan drug data base. Pigmented villonodular synovitis. ORPHA:66627

Pigmented villonodular synovitis (PVNS) is a rare benign proliferative disorder of the synovial membrane primarily affecting young adults (with a peak age of onset in the second to fourth decade of life) characterized by proliferative, locally invasive tumor-like lesions, usually involving a single joint, tendon sheath or bursa (most commonly the joints of the knee and hip and rarely others such as the ankle, shoulder and temporomandibular joints). It presents with pain and limitation of motion along with swelling, heat and tenderness over the involved joint, eventually leading to arthritic degeneration and significant locomotor deficit, if left untreated. PVNS can recur in patients even after treatment. 